\title{
Effects of Municipal Solid Waste Torrefaction and Classification Pretreatment on Hydrogen Chloride Release
}

\author{
Guangtao $\mathrm{Hu}^{1,2, \text { *, Xing Ning }}{ }^{2}$, Borui Zhu ${ }^{1}$, Shuang Wang ${ }^{1}$ \\ ${ }^{1}$ School of Energy Engineering, Yulin University, Yulin, China \\ ${ }^{2}$ School of Energy and Power Engineering, Xi'an Jiaotong University, Xi'an, China
}

Email address:

ylhuguangtao@126.com (Guangtao Hu)

${ }^{*}$ Corresponding author

\section{To cite this article:}

Guangtao Hu, Xing Ning, Borui Zhu, Shuang Wang. Effects of Municipal Solid Waste Torrefaction and Classification Pretreatment on Hydrogen Chloride Release. Science Journal of Energy Engineering. Vol. 9, No. 1, 2021, pp. 8-16. doi: 10.11648/j.sjee.20210901.12

Received: January 28, 2021; Accepted: February 17, 2021; Published: February 27, 2021

\begin{abstract}
The incineration treatment of municipal solid waste is widely used, but gas-phase hydrogen chloride $(\mathrm{HCl})$ generated during the incineration seriously threatens the heating surface of boiler tail, and even causes serious harm to environment. Through incineration experiments, this paper found that many factors (temperature, oxygen concentration, residence time and moisture content) affect the $\mathrm{HCl}$ emission characteristics in the process of municipal solid waste incineration treatment. In order to effectively cut back the $\mathrm{HCl}$ emission in incineration treatment of municipal solid waste, this paper proposes torrefaction and classification pretreatment of municipal solid waste. Torrefaction pretreatment has a significant inhibitory effect on $\mathrm{HCl}$ emission during the incineration of mixed municipal solid waste. At the same time, compared with the incineration treatment of mixed municipal solid waste, sawdust and plastic municipal solid waste of the same quality after classification pretreatment can effectively curb $\mathrm{HCl}$ emissions within the entire temperature range. In particular, $\mathrm{HCl}$ emissions are reduced by $35 \%$ during sawdust incineration treatment at $400^{\circ} \mathrm{C}$. Furthermore, by studying the reaction mechanics of $\mathrm{HCl}$ generation during combustion at different temperatures, and the reaction rate of $\mathrm{HCl}$ generation is: mixed municipal solid waste $>$ plastic $>$ sawdust. Therefore, this paper believes that torrefaction and classification pretreatment of mixed municipal solid waste is beneficial to inhibit the precipitation of chlorine during the incineration process and promotes the resource utilization of municipal solid waste, which is of significant significance for energy conservation and emission reduction.
\end{abstract}

Keywords: Municipal Solid Waste (MSW), Torrefaction, Classification, $\mathrm{HCl}$

\section{Introduction}

With the rapid development of our country economy, the output and growth rate of municipal solid waste ranks first in the world and grows at a rate of $8 \%-10 \%$ per year $[1,2]$. In order to avoid pollution to environment, it has become urgent to solve the rational treatment of municipal solid waste in the process of industrialization. Nowadays, municipal solid waste landfills, composting and incineration are the main treatments. Compared with the long time period of landfill and compost, however, incineration has advantages of reducing energy consumption, fast treatment speed and high temperature sterilization, and has become an important way to deal with municipal solid waste [3-6]. According to statistics, China's municipal solid waste production was 215,509 kilotons in
2017, a year-on-year increase of 5.7\% [5, 6]. Therefore, study of renewable cycle of municipal solid waste on the atmospheric environment management, energy conservation and emission reduction has far-reaching and long-term significance [7].

Because of the change of time and space, complex composition of municipal solid waste is complicated, diverse and uneven. Municipal solid waste mainly includes high chlorine waste plastic and medium-content chlorine timber, which mostly exist in the form of organic chlorine, but also includes a small number of inorganic chloride [8, 9]. Yang Z-C has found that due to the complexity of solid waste composition the distribution of chlorine varies, but the source of chlorine is consistent $[10,11]$. Thus, he has considered that it provides a theoretical basis for simulating a solid waste chlorine mixture. A large number of scholars have also shown 
that municipal solid waste in the middle-low temperature of $200 \sim 600^{\circ} \mathrm{C}$ commonly in the form of $\mathrm{HCl}$ release, and in high temperature mainly in the form of alkali metal chloride precipitation [12-14]. In the case of full combustion, chlorine in poly-vinyl chloride (PVC) substances can be converted into $\mathrm{HCl}$. When the presence of moisture, the increase of moisture in municipal solid waste can provide more $\mathrm{H}$ free radicals under high temperature combustion conditions, so that $\mathrm{C}$ free radicals have more opportunities to effectively collide with $\mathrm{H}$ free radicals [15]. The release has little effect at low temperature, but it aggravates the release of $\mathrm{HCl}$ during combustion at medium-high temperature. At the same time, mixed burning of municipal solid waste will show a higher $\mathrm{HCl}$ release [16-20]. Municipal solid waste incineration will release a large number of $\mathrm{HCl}$ pollutant gas, not only will corrode the metal pipe wall, shorten the service life of the equipment, at the same time, in the presence of carbon sources will produce dioxin precursors, which seriously harm to life and ecological environment $[21,22]$.

Thence, this paper analyzed that the difference in $\mathrm{HCl}$ release characteristics of municipal solid waste wet mixture and dry mixture (plastic and sawdust) in an orderly manner, thereby revealing influence of municipal solid waste torrefaction on the $\mathrm{HCl}$ release characteristics. Effects of multi-factors (combustion temperature, combustion oxygen concentration, combustion reaction time) were studied on the $\mathrm{HCl}$ release characteristics of municipal solid waste torrefaction mixture, and reaction kinetics of $\mathrm{HC} 1$ release was further proposed during combustion of municipal solid waste torrefaction mixture. After that, municipal solid waste is classified and then burned (plastic, sawdust) to analyze the $\mathrm{HCl}$ release characteristics. Finally, comparative research of influence of municipal solid waste torrefaction and classification on waste incineration pollutant emission based on the perspective of $\mathrm{HCl}$ release, which is aimed at providing a theoretical basis for municipal solid waste torrefaction and classification to reduce pollutant emission.

\section{Experimental System and Condition}

Take 2 3 mm municipal solid waste wet mixture (plastic and sawdust) and the classified wet waste (plastic, sawdust) sample particles for torrefaction in a drying oven at $105^{\circ} \mathrm{C}$ for $12 \mathrm{~h}$, and obtained a mixture of torrefaction and classified municipal solid waste. After connecting the system devices and checking the air tightness, the combustion experiment of each working condition is carried out in the two-dimensional quartz reaction tube. Simultaneously, the $\mathrm{NaOH}$ solution is used to collect the precipitation of $\mathrm{HCl}$ at the other end, and the measurement method is silver nitrate capacity method.

The silver nitrate capacity method can be frequently utilized to determine the content of chloride ions in the absorption liquid: first, the sample solution after sampling is transferred into a white porcelain dish and then the phenolphthalein indicator is added, and then the potassium chromate indicator is added when its solution red is just faded, finally, titrate 0.01 $\mathrm{mol} / \mathrm{L}$ silver nitrate standard solution under constant stirring until a non-disappearing light brick red color is produced. Another capacity absorption solution will be used for blank titration. The $\mathrm{HCl}$ concentration is calculated as follows:

$$
\mathrm{HCl}(m g)=\left(V-V_{0}\right) \times C_{\mathrm{AgNO}_{3}} \times 36.45 \times 1000
$$

$\mathrm{V}$ - the volume of silver nitrate standard solution consumed by the titration sample solution $(\mathrm{ml})$;

$\mathrm{V}_{0}$ - the volume of the silver nitrate standard solution consumed by the blank solution $(\mathrm{ml})$;

$\mathrm{C}\left(\mathrm{AgNO}_{3}\right)$ - concentration of silver nitrate standard solution $(\mathrm{mol} / \mathrm{L})$;

36.45-The mass of $\mathrm{HCl}$ equivalent to $1 \mathrm{~L}$ of $1 \mathrm{~mol} / \mathrm{L}$ silver nitrate standard solution $(\mathrm{g})$.

\section{Results and Discussion}

\subsection{HCl Release Characteristic of Municipal Solid Waste}

\subsubsection{Influence of Moisture Content on HCl Release Under Different Temperatures}

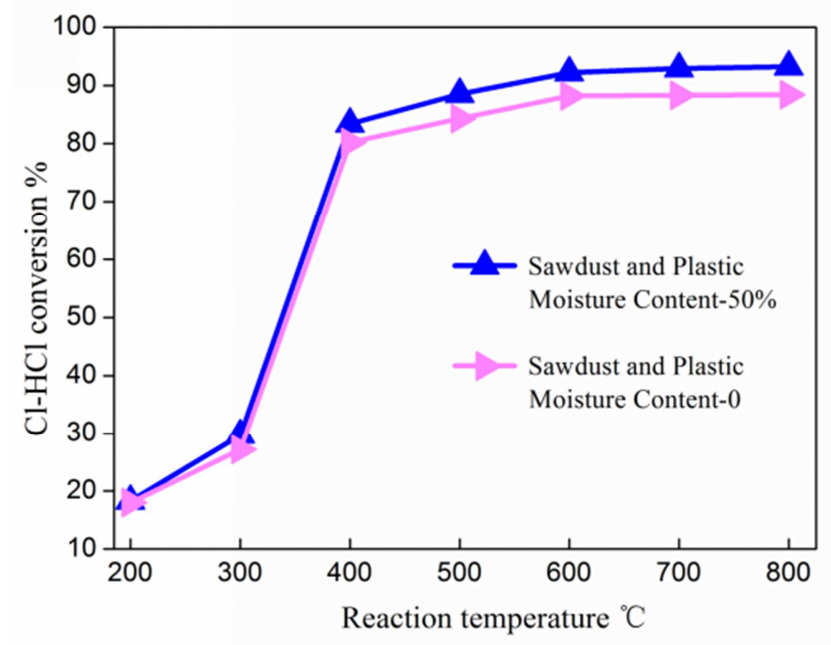

Figure 1. $\mathrm{Cl}-\mathrm{HCl}$ conversion rate of municipal solid waste mixture with different moisture contents when burned at different temperatures.

After municipal solid waste mixture is burned in an air atmosphere with a reaction time of $20 \mathrm{~min}, \mathrm{Cl}-\mathrm{HCl}$ conversion rate continues to increase within the temperature range of $200-700^{\circ} \mathrm{C}$. It is especially obvious that $\mathrm{Cl}-\mathrm{HCl}$ conversion rate of municipal solid waste is sharp at $300-400^{\circ} \mathrm{C}$, but the rise tends to be relatively flat at $400-600^{\circ} \mathrm{C}$, which is shown in Figure 1. Most of the chlorine is released in the form of $\mathrm{HCl}$ during combustion of municipal solid waste. Meanwhile, in two temperature ranges, the former is release of organic chlorine, and the latter is precipitation of inorganic chlorine $[14,23,24]$. It can be seen from the figure that combustion temperature affects the conversion of $\mathrm{Cl}-\mathrm{HCl}$, and the conversion rate of $\mathrm{Cl}-\mathrm{HCl}$ increases significantly with the increase of combustion temperature during combustion process. This is mainly due to the significant increase in the number of activated molecules in temperature, which increases the effective number of collisions between $\mathrm{H}$ free 
radical and $\mathrm{Cl}$ free radical within the residence time, and the chemical reaction is relatively sufficient, so the conversion rate of $\mathrm{CI}-\mathrm{HCl}$ is significantly increased $[5,16,25]$. In the process of municipal solid waste combustion, $\mathrm{HCl}$ has begun to be precipitated at $200^{\circ} \mathrm{C}$, and the conversion rate of $\mathrm{Cl}-\mathrm{HCl}$ is stable at $600^{\circ} \mathrm{C}$, indicating that majority of chlorine in municipal solid waste is precipitated at $600^{\circ} \mathrm{C}$.

What's more, the presence of moisture in combustion process of municipal solid waste remarkably accelerates release of chlorine in the waste, which indicates that part of chlorine release reaction occurs with the participation of moisture vapor. When moisture exists, effect of chlorine precipitation from municipal solid waste combustion is that combustion temperature is meaningfully reduced with the same chlorine precipitation rate. When the presence of moisture, sawdust waste that is not free of volatile chlorine released $\mathrm{HCl}$ gas during the incineration process after the inorganic chloride salt is obtained by transfer [15]. because of the existence of kitchen waste with high moisture content from municipal solid waste, the amount of $\mathrm{HCl}$ released during combustion of municipal solid waste increases. Therefore, reducing the moisture content of kitchen waste through torrefaction is a technical measure to decrease precipitation of chlorine during the combustion of municipal solid waste.

\subsubsection{Influence of Burning Time on HCl Release Under Same Temperatures}

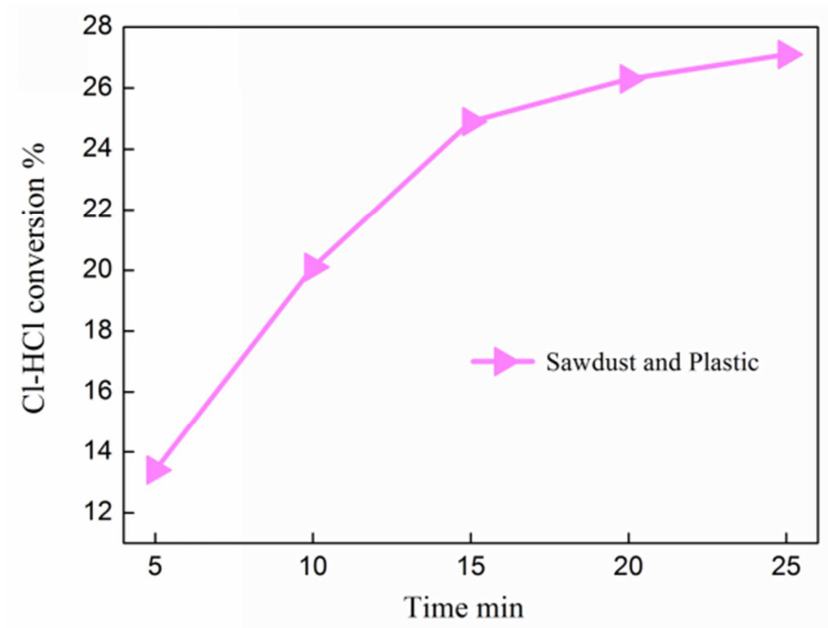

Figure 2. $\mathrm{Cl}-\mathrm{HCl}$ conversion rate of municipal solid waste mixture with different reaction time when burned at $300^{\circ} \mathrm{C}$.

Municipal solid waste mixture is burned for different time under $300^{\circ} \mathrm{C}$ in an air atmosphere, and its $\mathrm{Cl}-\mathrm{HCl}$ conversion rate is related to the duration of stay in the furnace. As can be seen from Figure 2, as $\mathrm{Cl}-\mathrm{HCl}$ conversion rate increases rapidly with the increase of the length of stay, and the longer the stay, the fuller the reaction. Furthermore, the process of $\mathrm{HCl}$ release of municipal solid waste mixture in combustion process is obviously divided into two stages. From beginning of experiment until $15 \mathrm{~min}$, most of chlorine precipitated by municipal solid waste mixture after heating process is active organic chlorine. At the same time, the precipitation rate at this stage is very fast, and most of municipal solid waste mixture of chlorine has been analyzed by $15 \mathrm{~min}$. But $\mathrm{HCl}$ precipitated after 15 min may be precipitation of chlorine in the form of chloride ions, which is relatively slow. This is mainly due to the highest chlorine content of plastic waste, meanwhile, the de-chlorination and combustion process of PVC will occur in the temperature range of $220-320^{\circ} \mathrm{C}$, resulting in a large number of active organic chlorine production [26]. But, inorganic chlorine is relatively stable, its chlorine analysis is slow. Therefore, $\mathrm{HCl}$ release rate during combustion process of municipal solid waste mixture 15 minutes ago is relatively large, and $\mathrm{HCl}$ release is more. In practical engineering applications, municipal solid wastes mixture, especially the residence time of waste plastic in high temperature areas, should be reduced as much as possible, which can significantly slow down generation of $\mathrm{HCl}$, thereby cutting down high temperature corrosion of $\mathrm{HCl}$ on the boiler over-heater.

\subsubsection{Influence of Oxygen Content on HCl Release Under Same Temperatures}

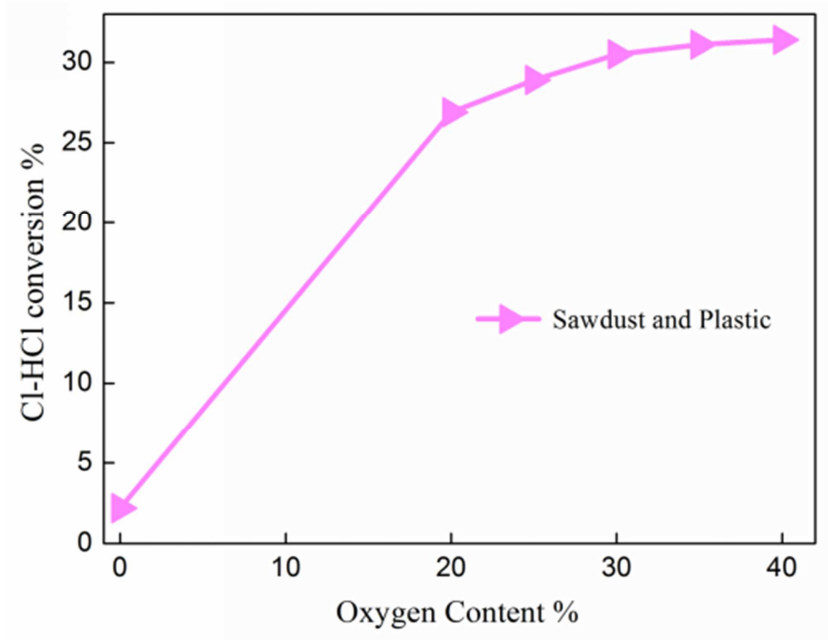

Figure 3. $\mathrm{Cl}-\mathrm{HCl}$ conversion rate of municipal solid waste mixture with different oxygen concentrations when burned at $300^{\circ} \mathrm{C}$.

There are oxidizing and reducing alternating atmospheres during combustion process of municipal solid waste mixtures, and different atmospheres have a serious impact on the precipitation of chlorine. In order to study the effect of alternating atmosphere on precipitation of chlorine during combustion process of municipal solid waste mixtures, $\mathrm{Cl}-\mathrm{HCl}$ conversion rate of different oxygen concentrations was analyzed at a combustion temperature of $300^{\circ} \mathrm{C}$ and a reaction time of $20 \mathrm{~min}$, the results shown in Figure 3. In the pyrolysis reaction where the oxygen concentration is zero, the $\mathrm{Cl}-\mathrm{HCl}$ conversion rate of the municipal solid waste mixture is about $2 \%$, indicating that a certain amount of chlorine precipitation exists at $300^{\circ} \mathrm{C}$, which is typically due to part of organic chlorine in municipal solid waste mixture has chlorine precipitation during pyrolysis process. With the increase of oxygen, chlorine emission rate increased to about $30 \%$, and 
chloride generation changed greatly. As the transformation of atmosphere from weak reductive atmosphere to strong oxidation atmosphere, chlorine precipitation rate increased significantly. Oxygen provides more active particles and sites for the combustion process of municipal solid waste mixtures, so the increase of oxygen concentration effectively increased combustion intensity of municipal solid waste mixture, and brought more $\mathrm{HCl}$ release. Therefore, oxygen plays a vital role in the thermal conversion of municipal solid waste mixture chlorine. At the same time, it can be seen that the larger the amount of oxygen, the more conducive to precipitation of $\mathrm{HCl}$, and in order to effectively inhibit the precipitation of $\mathrm{HCl}$, the amount of oxygen cannot be too high.

\subsubsection{Reaction Kinetics of HCl Formation During the Combustion of Municipal Solid Waste Mixture}

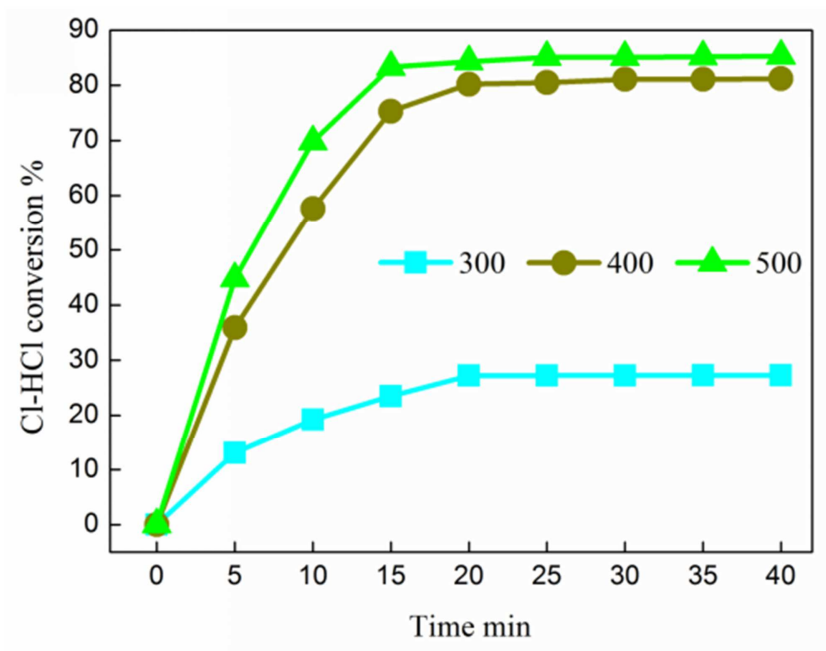

Figure 4. The relationship between burning time and the conversion rate of $\mathrm{Cl}-\mathrm{HCl}$ in municipal solid waste mixture at different temperatures.

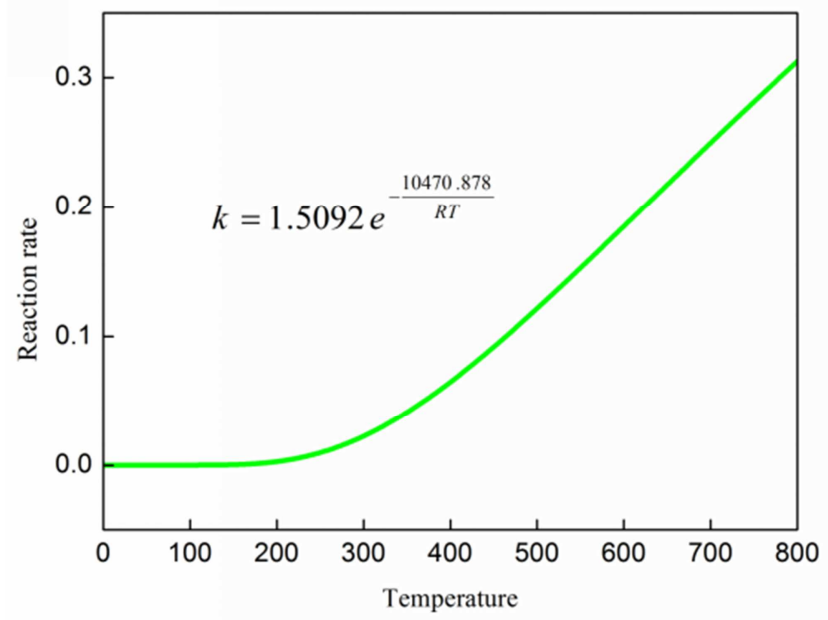

Figure 5. Reaction kinetic equation of $\mathrm{HCl}$ generated during combustion process of municipal solid waste mixture.

Suppose that municipal solid waste mixture is burned in a tube furnace, and when air passes through a two-dimensional quartz reaction tube at a constant flow rate, the chlorine in municipal solid waste mixture is basically precipitated in the form of $\mathrm{HCl}$ during chlorine generation reaction. The relationship between burning time and the conversion rate of $\mathrm{Cl}-\mathrm{HCl}$ in municipal solid waste mixture at different temperatures is shown in Figure 4. The reaction kinetic rate at different temperatures can also be calculated using the Arrhenius equation:

$$
\text { Arrhenius equation: } k=A e^{-\frac{E}{R T}}
$$

Molar gas constant: $\mathrm{R}=8.134 \mathrm{KJ} / \mathrm{mol}$

Reaction kinetic equation of $\mathrm{HCl}$ generated during combustion process of municipal solid waste mixture is shown in Figure 5. $\left(k=1.5092 e^{-\frac{10470.878}{R T}}\right)$

\subsection{HCl Release Characteristics of Sawdust and Plastic}

\subsubsection{Influence of Moisture Content on the Release of $\mathrm{HCl}$}

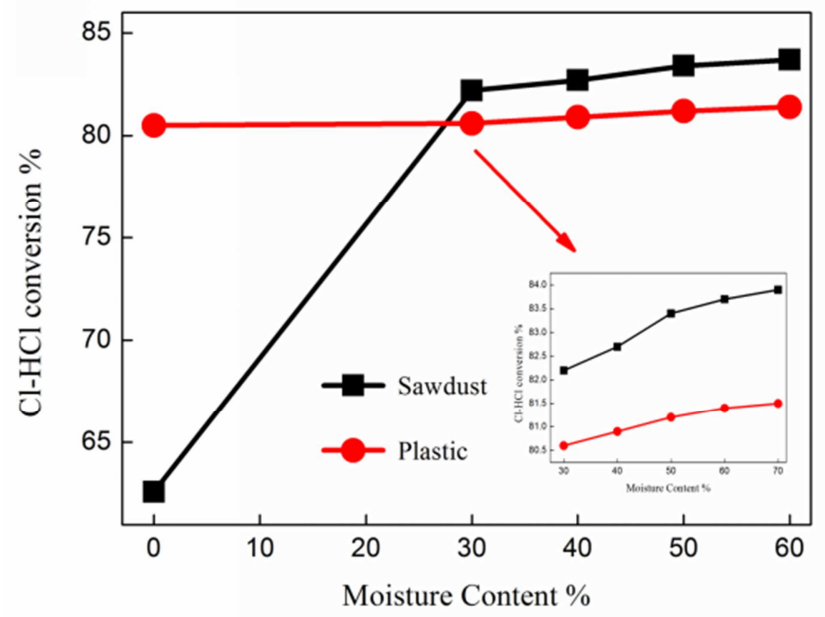

Figure 6. $\mathrm{Cl}-\mathrm{HCl}$ conversion rate of municipal solid waste (sawdust, plastic) with different moisture contents when burned at $500^{\circ} \mathrm{C}$.

Earlier in this paper, release of $\mathrm{HCl}$ in combustion process of municipal solid waste mixture at different temperatures and moisture contents was studied, and it was pointed out that the presence of moisture vapor aggravates the chlorine extraction in combustion process of municipal solid waste mixture. Nowadays, release of $\mathrm{HCl}$ in combustion process of the classified municipal solid waste (sawdust, plastic) at $500^{\circ} \mathrm{C}$ in different moisture vapor content is studied separately, results is shown in Figure 6. With the increase of moisture vapor content, the change of sawdust is particularly prominent compared with the change of $\mathrm{Cl}-\mathrm{HCl}$ conversion rate of plastic. When moisture vapor content increased from 0 to $30 \%$, the $\mathrm{Cl}-\mathrm{HCl}$ conversion rate of sawdust increased by $30.2 \%$. Furthermore, with the increase of moisture vapor content, the $\mathrm{Cl}-\mathrm{HCl}$ conversion rate of sawdust tends to level off. However, for the $\mathrm{Cl}-\mathrm{HCl}$ conversion rate of plastics, increasing in moisture vapor content does not change much, and its fluctuations range is even smaller than that of sawdust. Release of most of the organic chlorine in PVC in the high-chlorine plastic basically ends at $500^{\circ} \mathrm{C}$, and its inorganic chlorine is relatively small, so the increase in moisture vapor 
content has little effect on it. However, it is different for medium-chlorine sawdust. With the increase of moisture vapor content, under the hydrolysis of chlorinated minerals, sawdust that non-volatile chlorine-free sawdust by transfer to obtain inorganic chlorine salt, and the solid chlorine equivalent into gaseous chlorine in the incineration process to analyze $\mathrm{HCl}$.

\subsubsection{Influence of Combustion Temperature on the Release of $\mathrm{HCl}$}

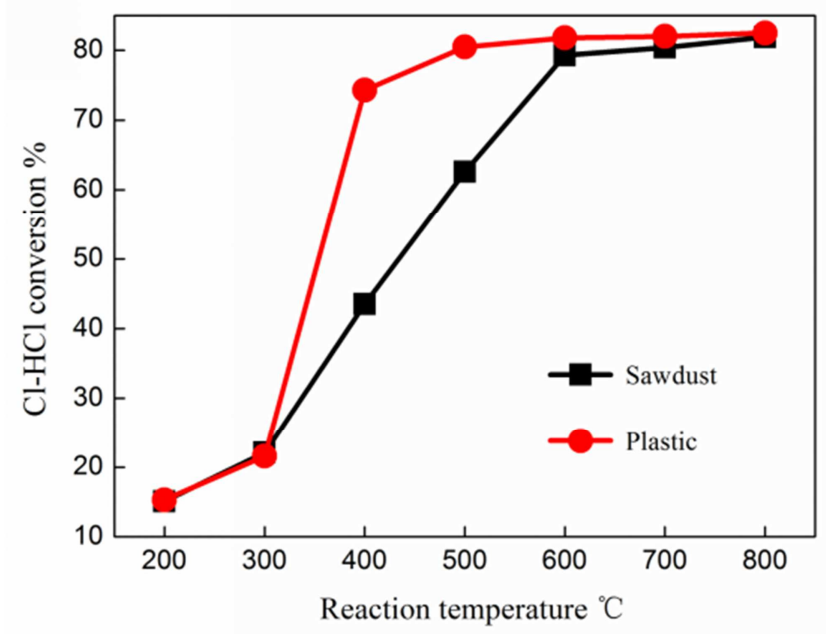

Figure 7. Cl-HCl conversion rate of municipal solid waste (sawdust, plastic) with different combustion temperatures.

The $\mathrm{Cl}-\mathrm{HCl}$ conversion rate of the classified municipal solid waste at different combustion temperatures is shown in Figure 7. After sawdust combustion in the air atmosphere of $20 \mathrm{~min}$, the $\mathrm{Cl}-\mathrm{HCl}$ conversion rate is continuously improved in the temperature range of 200 to $600^{\circ} \mathrm{C}$, especially the $\mathrm{Cl}-\mathrm{HCl}$ conversion rate has reached $50 \%$ at about 430 , and the $\mathrm{Cl}-\mathrm{HCl}$ conversion rate in the temperature range of 600 to $800^{\circ} \mathrm{C}$ is flat. The large proportion of the chlorine source of medium-chlorinated sawdust that precipitates in the form of inorganic chlorine at medium-low temperatures of $200-600^{\circ} \mathrm{C}$. However, for plastic, the $\mathrm{Cl}-\mathrm{HCl}$ conversion rate rises sharply in the temperature range of $300-400^{\circ} \mathrm{C}$, and the $\mathrm{Cl}-\mathrm{HCl}$ conversion rate is as high as $74 \%$ at $400^{\circ} \mathrm{C}$, and the $\mathrm{Cl}-\mathrm{HCl}$ conversion rate has flattened in the temperature range of 500 to $800^{\circ} \mathrm{C}$. This is mainly due to the fact that the precipitation of most organic chlorine in high-chlorine plastics, and the proportion of inorganic chlorine is relatively low. At the same time, through the slope, it can be found that the order of $\mathrm{Cl}-\mathrm{HCl}$ conversion rate in the temperature range of $200-600^{\circ} \mathrm{C}$ is: plastic $>$ sawdust. The temperature range of $\mathrm{HCl}$ released by inorganic chlorine in sawdust during combustion process is usually $200-600^{\circ} \mathrm{C}$, while the temperature range of $\mathrm{HCl}$ released by organic chlorine in plastics during combustion is relatively narrow but the conversion is faster. Therefore, the combustion temperature has a certain effect on the $\mathrm{HCl}$ gas phase migration transformation of plastic and sawdust with different chlorine content. As the temperature increases, so does the conversion rate of all chlorine sources $\mathrm{Cl}-\mathrm{HCl}$, but the organic chlorine $\mathrm{Cl}-\mathrm{HCl}$ conversion rate is higher at the same temperature. Thus, the classification of municipal solid waste is beneficial to define the balance point of thermal energy conversion and reduction of $\mathrm{HCl}$ release, thereby further promoting the effective utilization of municipal solid waste resources.

\subsubsection{Influence of Burning Time on the Release of $\mathrm{HCl}$}

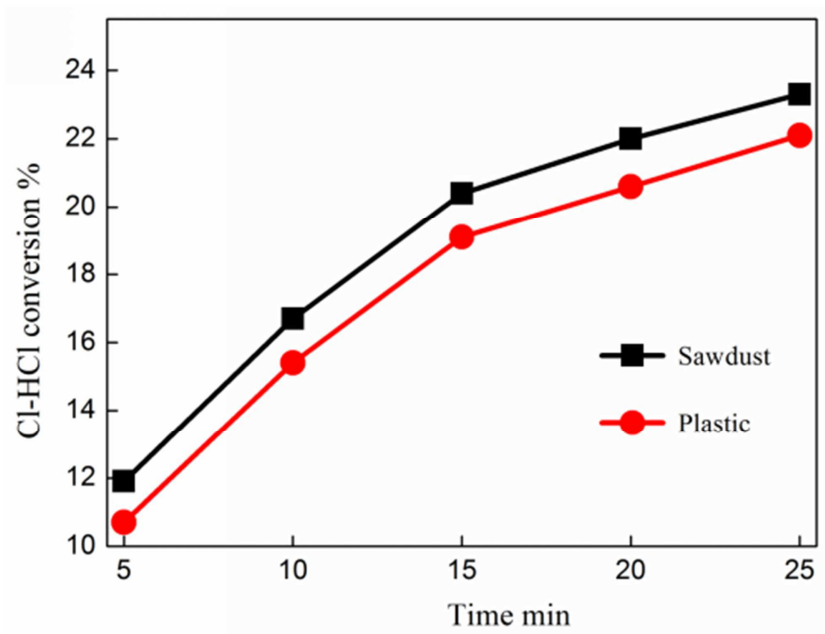

Figure 8. Cl-HCl conversion rate of municipal solid waste (sawdust, plastic) with different reaction time.

Figure 8 shows classification of municipal solid waste at a different reaction time $\mathrm{Cl}-\mathrm{HCl}$ conversion rate at $300^{\circ} \mathrm{C}$ in an air atmosphere. The conversion rate of chlorine in sawdust is higher than that of plastic, and the conversion rate of $\mathrm{Cl}-\mathrm{HCl}$ in $5 \mathrm{~min}$ is about $12 \%$. The chlorinated sawdust can precipitate $\mathrm{HCl}$ in a short time when temperature rises rapidly. Meanwhile, for plastic, the $\mathrm{HCl}$ release law is roughly the same as that of sawdust when incinerated. However, it is worth noting that the $\mathrm{Cl}-\mathrm{HCl}$ conversion rate of high-chlorine plastics is relatively low in $300^{\circ} \mathrm{C}$ air atmosphere after the classification of municipal solid waste. The precipitation of gaseous chloride is related to combustion temperature and residence time. It can be seen from the figure that at the same combustion temperature, with the increase of residence time, both the release amount and conversion rate of combustible solid waste $\mathrm{HCl}$ show an increasing trend. Furthermore, regardless of whether it is high-chlorine plastic or medium-chlorine sawdust, the $\mathrm{Cl}-\mathrm{HCl}$ conversion rate shows a two-stage change as the combustion time increases, and the $\mathrm{Cl}-\mathrm{HCl}$ conversion rate increases sharply within $5-15 \mathrm{~min}$. But the $\mathrm{Cl}-\mathrm{HCl}$ conversion rate is relatively slow within 5-25 min. The release of $\mathrm{HCl}$ from the organic chlorine during the thermal conversion process, which is mainly in the early stage of the reaction, and its release is relatively concentrated, while the precipitation of chlorine becomes slow with the increase of time, and the precipitation of inorganic chlorine is mainly at this time. Organic and inorganic chlorine combustible solid wastes release $\mathrm{HCl}$ at a different rate and concentration time period, which illustrates the difference in the internal mechanism of $\mathrm{HCl}$ release, and has certain guiding significance for the classification treatment of 
municipal solid wastes.

\subsubsection{Influence of Oxygen Concentration on the Release of $\mathrm{HCl}$}

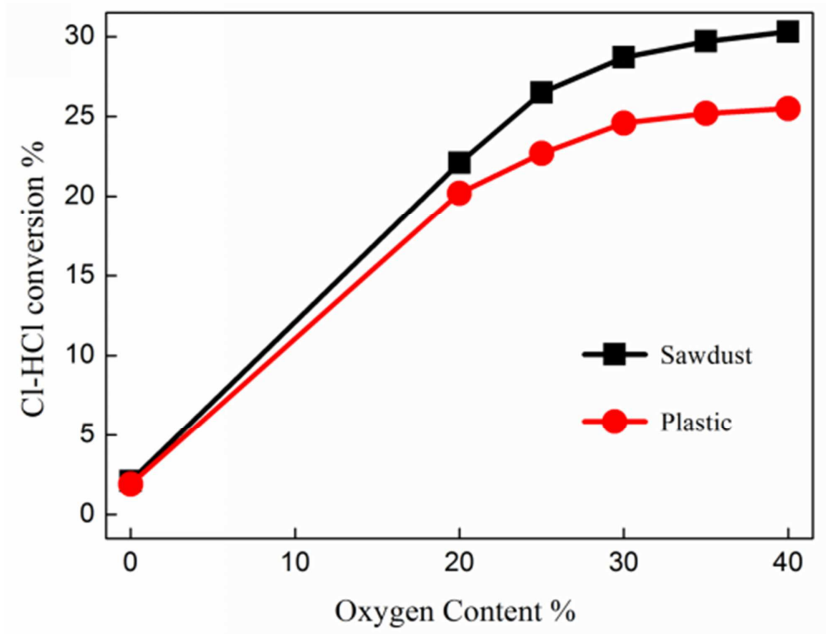

Figure 9. $\mathrm{Cl}-\mathrm{HCl}$ conversion rate of municipal solid waste (sawdust, plastic) with different oxygen concentrations.

Sawdust and plastic have oxidizing and reducing atmosphere changes during the combustion process, in view of the municipal solid wastes high volatility and combustion characteristics, sawdust and plastic in combustion process of change of oxidation and reduction atmosphere is more obvious, therefore, it is very important to study the effect of atmosphere on chlorine analysis. Figure 9 shows the $\mathrm{Cl}-\mathrm{HCl}$ conversion rate of different oxygen concentrations of each material at a combustion temperature of $300^{\circ} \mathrm{C}$ at 20 min after the classification of municipal solid waste. The larger oxygen concentration is beneficial to precipitation of chlorine in sawdust and plastic during combustion. When oxygen concentration is zero, that is pyrolysis process, the conversion rates of $\mathrm{Cl}-\mathrm{HCl}$ for sawdust and plastic are $2.2 \%$ and $1.9 \%$, respectively. At the same time, the $\mathrm{Cl}-\mathrm{HCl}$ conversion rate of

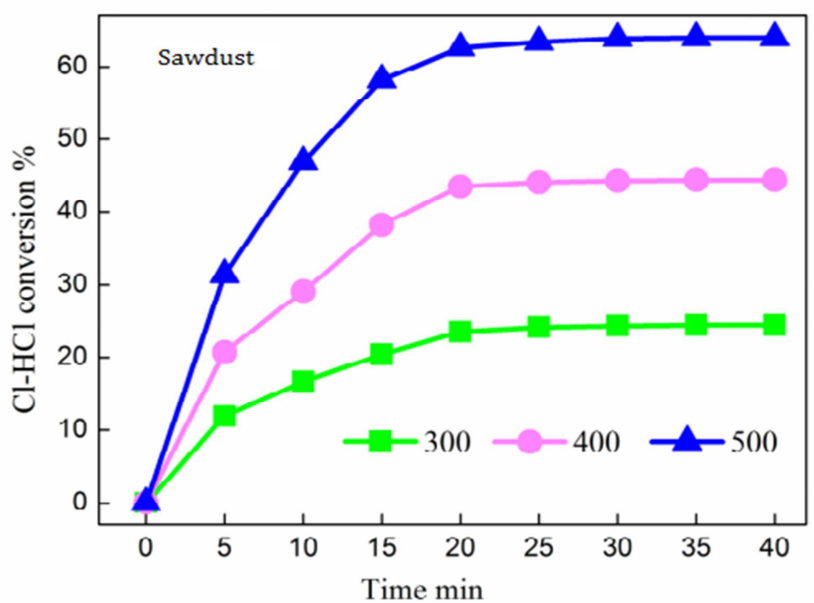

sawdust is significantly higher than that of plastics in the entire oxygen concentration range. When oxygen concentration is low, furnace presents a reducing atmosphere and chlorine precipitation rate is low. But, when the amount of oxygen increases, the conversion rate of $\mathrm{Cl}-\mathrm{HCl}$ increases, which shows that combustion of material is more beneficial to promote the conversion of $\mathrm{Cl}-\mathrm{HCl}$, and increasing in the amount of oxidation is beneficial to the conversion of chlorine However, within the range of $30-40 \%$ oxygen content, the increase in the $\mathrm{Cl}-\mathrm{HCl}$ conversion rate of each material tends to be flat, mainly because the decisive factor affecting the $\mathrm{Cl}-\mathrm{HCl}$ conversion in inorganic chlorine is temperature. Therefore, addition of oxygen in the thermal conversion process of combustible solid waste accelerates the decomposition of materials. However, it can also be seen from the figure that changes in oxygen concentration have different promotion effects on $\mathrm{HCl}$ during the thermal conversion of inorganic and organic chlorine combustible solid wastes.

\subsubsection{Reaction Kinetics of $\mathrm{HCl}$ Formation During the Combustion of Sawdust and Plastic}

Suppose that sawdust and plastic are burned in a tube furnace, and when air passes through a two-dimensional quartz reaction tube at a constant flow rate, the chlorine in the sawdust and plastic basically precipitates in the form of $\mathrm{HCl}$ during the process of generating chlorine. Figure 10 show the relationship between the burning time and the $\mathrm{Cl}-\mathrm{HCl}$ conversion rate in sawdust and plastic at different temperatures. The Arrhenius equation can also be used to calculate the reaction kinetic rate of $\mathrm{HCl}$ generated in the combustion process:

Arrhenius equation: $k=A e^{-\frac{E}{R T}}$

Molar gas constant: $\mathrm{R}=8.134 \mathrm{KJ} / \mathrm{mol}$

The reaction kinetic equation of $\mathrm{HCl}$ generated during the combustion of sawdust and plastic are shown in Figure 11. (sawdust: $k=0.2306 e^{-\frac{6148.584}{R T}}$, plastic: $k=0.9009 e^{-\frac{9746.107}{R T}}$ )

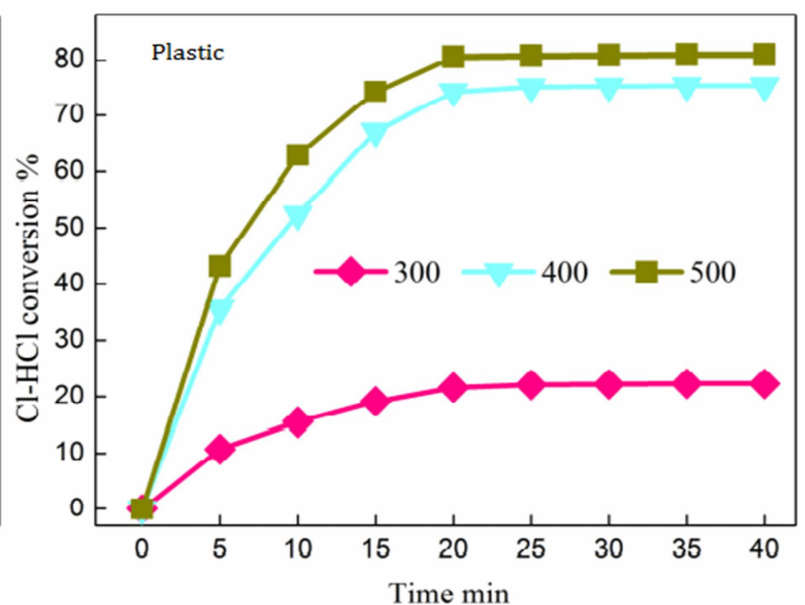

Figure 10. The relationship between the burning time and the Cl-HCl conversion rate in sawdust and plastic at different temperatures. 

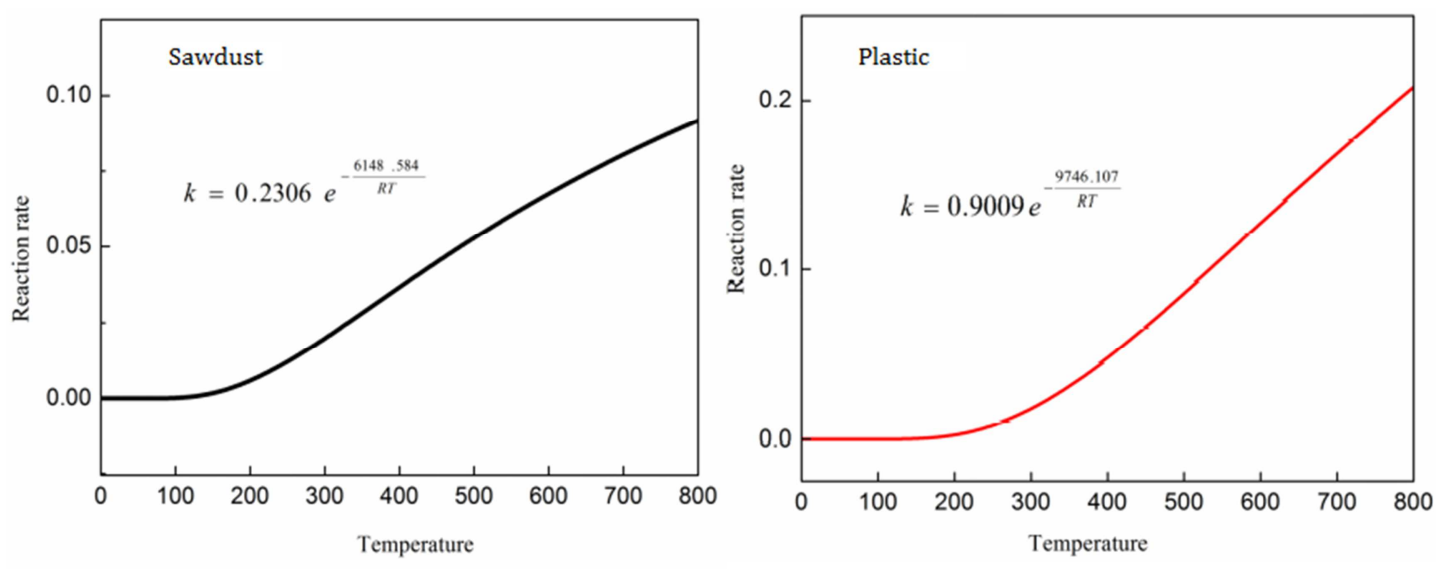

Figure 11. The reaction kinetic equation of $\mathrm{HCl}$ generated during the combustion of sawdust and plastic.

\subsection{Effect of Torrefaction and Classification on the Release of HCl from Municipal Solid Waste}

The inhibitory effect of torrefaction and classification on the release of chlorine during combustion of municipal solid waste is shown in Figure 12, Figure 13 and Figure 14.

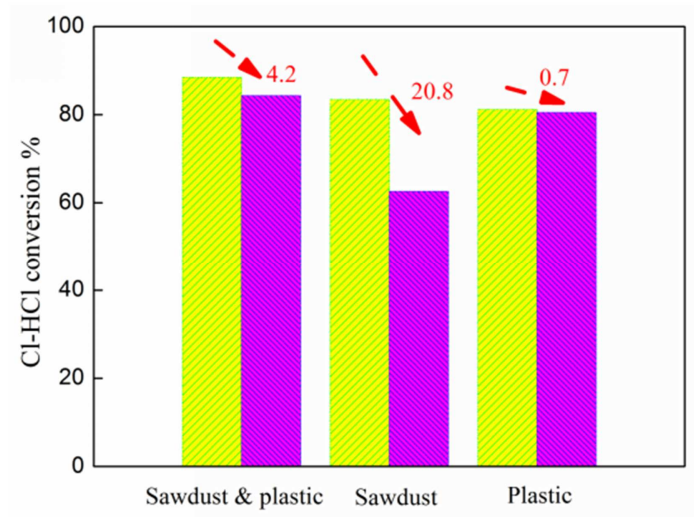

Figure 12. The amount of chlorine precipitation before and after the torrefaction of mixed, sawdust and plastic municipal solid waste with $50 \%$ moisture content at $500^{\circ} \mathrm{C}$.

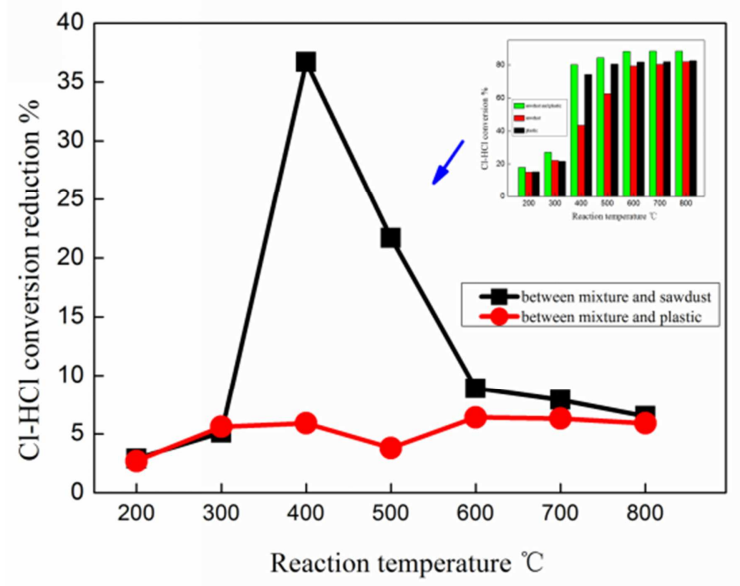

Figure 13. The difference between the chlorine precipitation content of sawdust and plastic municipal solid waste after classification and the chlorine precipitation content of unclassified mixed municipal solid waste during the combustion process at different temperatures.

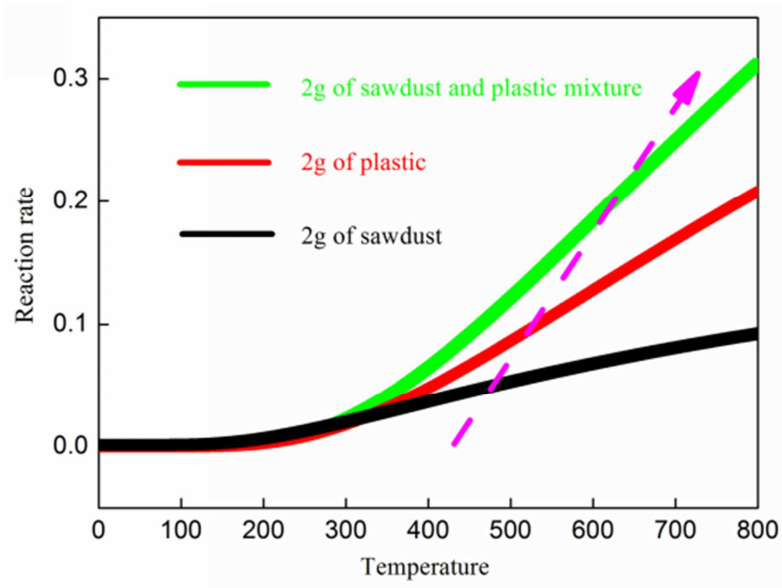

Figure 14. The comparison of the chlorine precipitation reaction kinetics of sawdust and plastic municipal solid waste after classification under the same quality with that of unsorted mixed municipal solid waste.

Figure 12 shows the amount of chlorine precipitation before and after the torrefaction of mixed, sawdust and plastic municipal solid waste with $50 \%$ moisture content at $500^{\circ} \mathrm{C}$. Compared with the original municipal solid waste, release of $\mathrm{HCl}$ after torrefaction municipal solid waste in the combustion process is reduced, and the total release is also greatly decreased, indicating that torrefaction as a pretreatment means can indeed curb the release of municipal solid waste in the furnace combustion process $\mathrm{HCl}$, thereby preventing the risk of chlorine chloride from municipal solid waste to the boiler heat surface corrosion. Some fuels disappear in the gas phase in the form of volatile hydrocarbons during the torrefaction pretreatment, which can release part of the chlorine in the form of $\mathrm{CH}_{3} \mathrm{Cl}$ [27]. Simultaneously, $\mathrm{CH}_{3} \mathrm{Cl}$ competes with $\mathrm{HCl}$ for chlorine freelance produced during combustion in urban solid waste, which leads to the chlorine content of the municipal solid waste after torrefaction pretreatment is lower than chlorine content of the original municipal solid waste, and a significantly lower $\mathrm{HCl}$ resulting from $\mathrm{HCl}$ from combustion of primary municipal solid waste [21, 28]. Furthermore, it can be seen from Figure 12 that the reduction of chlorine precipitation during combustion process after the torrefaction pretreatment of plastic solid waste is less reduced, 
but the reduction of chlorine precipitation is the largest after the torrefaction pretreatment of sawdust solid waste, while mixed municipal solid waste is centered. This is mainly because part of the chlorine in sawdust solid waste torrefaction pretreatment is fixed by alkali metals, alkaline earth metals and their oxides in the ash after the sawdust is burned, therefore, its inhibitory effect is the most obvious [29] The torrefaction of municipal solid waste has an important inhibitory effect on precipitation of chlorine and effectively improves the incineration treatment.

Figure 13 shows the difference between the chlorine precipitation content of sawdust and plastic municipal solid waste after classification and the chlorine precipitation content of unclassified mixed municipal solid waste during the combustion process at different temperatures. Figure 14 shows the comparison of the chlorine precipitation reaction kinetics of sawdust and plastic municipal solid waste after classification under the same quality with that of unsorted mixed municipal solid waste.

A large number of previous studies have shown that chlorine sources of municipal solid waste mainly derived from plastic with high chlorine content and sawdust with medium chlorine content $[30,31]$. However, $\mathrm{HCl}$ release of municipal solid waste after classification was revealed in this paper. As can be seen from Figure 13, $\mathrm{HCl}$ release of sawdust after classification at $400^{\circ} \mathrm{C}$ has the largest difference with $\mathrm{HCl}$ release of mixed municipal solid waste under the same mass, and classification has the most prominent inhibitory effect on its $\mathrm{HCl}$ release. At the same time, compared with classified plastic, the amount of $\mathrm{HCl}$ released during the combustion of sawdust after classification in the full temperature range is also significantly reduced. However, in general, $\mathrm{HCl}$ emission of municipal solid wastes of the same quality after classification decreased. In fact, any change in the composition of municipal solid waste will significantly affect the combustion and further change the amount of $\mathrm{HCl}$ released. The classified municipal solid waste has a single chlorine source structure, stable incineration, and the coordination of organic chlorine and inorganic chlorine is hindered, thereby effectively reducing the release of $\mathrm{HCl}[32,33]$. Further known from Figure 14, reaction kinetics relationship generated by $\mathrm{HCl}$, when the combustion temperature is higher than $300^{\circ} \mathrm{C}$, the $\mathrm{HCl}$ generation of mixed municipal solid waste is significantly increased, and then at the same temperature the $\mathrm{HCl}$ growth of the size of the relationship is: mixed >plastic $>$ sawdust. Therefore, the classified combustion treatment of municipal solid waste is beneficial to curb the release of $\mathrm{HCl}$, thereby further reducing the risk of corrosion on the heating surface of the boiler, and it is of great significance to suppress pollutant emissions.

\section{Conclusions}

Mixed municipal solid waste could release more $\mathrm{HCl}$ during combustion treatment. When municipal solid waste contains moisture, it will further increase the precipitation of $\mathrm{HCl}$, and torrefaction can effectively reduce the precipitation of chlorine, especially for inorganic chlorine at high temperatures. At the same time, it was found that the amount of $\mathrm{HCl}$ released from sawdust and plastic was significantly decreased during the combustion process when municipal solid waste was classifying, and the classification inhibited the release of $\mathrm{HCl}$. Therefore, the orderly adjustment of combustion conditions, the introduction of torrefaction and classified pretreatment can effectively lower the amount of $\mathrm{HCl}$ released during the incineration of municipal solid waste, thereby effectively reducing the risk of corrosion on the heating surface of the boiler, which further promotes energy conservation and emission reduction.

\section{Funding}

This research was funded by Guang-tao $\mathrm{Hu}$ grant number No. 19JK1008 and 2019-87-2. And The APC was funded by Guang-tao Hu.

\section{Conflicts of Interest}

All the authors do not have any possible conflicts of interest.

\section{Acknowledgements}

This work was supported by the 2019 Special Scientific Research Plan at Shaanxi Provincial Department of Education (No. 19JK1008) and Yu-lin City's 2019 Science and Technology Plan (2019-87-2).

\section{References}

[1] He, M. Y.; Xiao, B.; Liu, S. M.; Hu, Z. Q.; Guo, X. J.; Luo, S. Y.; Yang, F. Syngas production from pyrolysis of municipal solid waste (MSW) with dolomite as downstream catalysts. $J$. Anal. Appl. Pyrolysis 2010, 87, 181-187.

[2] Zhou, H.; Meng, A. H.; Long, Y. Q.; Li, Q. H.; Zhang, Y. G. An overview of characteristics of municipal solid waste fuel in China: physical, chemical composition and heating value. Renew. Sust. Energ. Rev. 2015, 46, 107-122.

[3] Guo, X. F.; Yang, X. L.; Li, H. B.; Wu, C. Z.; Chen, Y.; Li, F.; Xie, K. C. Release of hydrogen chloride from combustibles in municipal solid waste. Environ. Sci. Technol. 2001, 35, 001-005.

[4] Abascal, M. B.; Blaesing, M.; Ninomiya, Y.; Mueller, M. Influence of Steam, Hydrogen Chloride, and Hydrogen Sulfide on the Release and Condensation of Cadmium in Gasification. Energ. Fuel. 2016, 55, 943-953.

[5] Ren, X.; Meng, X.; Panahi A.; Rokni, E.; Sun, R.; Levendis, Y. A. Hydrogen Chloride Release From Combustion of Corn Straw in a Fixed Bed. J. Energ. Resour. Technol. 2018, 140, 011-019.

[6] Long, Y. Present Situation and Treatment Method of Solid Waste. Energ. Conserv. Environ. Protection 2019, 4, 074-075.

[7] Mao, K.; Ding, H. X.; Cui, X. A. Summary of flue gas treatment technology of municipal waste incineration power generation plants and recommendations of control optimization. Pollution Control Technol. 2018, 31, 014-017. 
[8] BJÖRKMAN, E.; STRÖMBERG, B. Release of chlorine from biomassat pyrolysis and gasification conditions. Energ. Fuel. 2014, 11, 026-032.

[9] Yu, M.; Dong, Y.; Wang, P.; Ma, C. Y. Progress of effects of chloride on mercury removal for coal-fired flue gas. Chem. Ind. Eng. Prog. 2012, 31, 610-614.

[10] Li, X. D.; Yang, Z. C.; Yan, J. H.; Lu, S. Y.; Ni, M. J.; Cen, K. F. $\mathrm{HCl}$ Emission During chloride Wastes Combustion Process. J. Chem. Ind. Eng. 2003, 54, 486-489.

[11] Li, X. D.; Yang, Z. C.; Yan, J. H.; Lu, S. Y.; Ni, M. J.; Cen, K. F. Effects Of Chlorine On $\mathrm{HCl}$ And PCDD/Fs Emission In A MSW Incinerator. J. Eng. Thermophs. 2003, 24, 047-050.

[12] Hua, Z.; Yu, S. Y.; Shao, L. M.; He, P. J. Estimating source strengths of $\mathrm{HCl}$ and $\mathrm{SO}_{2}$ emissions in the flue gas from waste incineration. J. Environ. Sci. 2019, 75, 370-377.

[13] Frigge, L.; Ströhle, J.; Epple, B. Release of sulfur and chlorine gas species during coal combustion and pyrolysis in an entrained flow reactor. Fuel 2016, 201, 105-110.

[14] Wey, M. Y.; Liu, K. Y.; Yu, W. J.; Lin, C. L.; Chang, F. Y. Influences of chlorine content on emission of $\mathrm{HCl}$ and organic compounds in waste incineration using fluidized beds. Waste Manage. 2008, 28, 406-415.

[15] Sun, R.; Ismail, T. M.; Ren, X.; El-Salam, M. A. Numerical and experimental studies on effects of moisture content on combustion characteristics of simulated municipal solid wastes in a fixed bed. Waste Manage. 2015, 39, 980-986.

[16] Meng, X.; Sun, R.; Ismail, T. M.; Yuan, H.; Zhou, W.; Ren, X. Parametric studies on corn combustion characteristics in a fixed Bed: Primary air flow rate and different corn lengths. Appl. Therm. Eng. 2017, 126, 702-716.

[17] Huang, Y. L.; Liu, X. J.; Zhang, Q. C.; Xu, Y.; Kunte, H.; Roland, D. M. Hydrogen release from carbon steel in chloride solution under anodic polarization. Int. J. Hydrog. Energ. 2020, 45, 307-315.

[18] Tran, M. P.; Gonzalez, A. P.; Beitia, C.; Lundgren, J.; Moon, S I.; Fontaine, H. Deposition of hydrogen chloride gas on copper wafer depending on humidity and $\mathrm{HCl}$ concentration. Microelectron. Eng. 2019, 207, 001-006.

[19] Dawe, K. R.; Furlani, T. C.; Kowal, S. F.; Kahan, T. C.; Vandenboer, C.; Young, J. Formation and emission of hydrogen chloride in indoor air. Indoor Air 2019, 29, 070-078.

[20] Porbatzki, D.; Stemmler, M.; Müller, M. Release of inorganic trace elements during gasification of wood, straw, and miscanthus. Biomass Bioenerg. 2011, 35, 079-086.

[21] Zhang, C. X; Wang, Y. X.; Yang, Z. H.; Xu, M. H. Chlorine emission and dechlorination in co-firing coal and the residue from hydrochloric acid hydrolysis of Discorea zingiberensis. Fuel 2006, 85, 034-040.

[22] Wu, P.; Yu, C. J.; Bai, J.; Li, L. M.; Huang, F. Mechanism Study of Chlorine Release During Biomass Pyrolysis. Proc. Chin. Soc. Electrical. Eng. 2013, 33, 001-007.

[23] Lopez, A.; Marco, I. D.; Caballero, B. M.; Laresgoiti, M. F.; Adrados, A. Dechlorination of fuels in pyrolysis of PVC containing plastic wastes. Fuel Proc. Technol. 2011, 92, 253-260.

[24] Yuan, G.; Chen, D.; Yin, L.; Wang, Z.; Zhao, L.; Wang, J. Y. High efficiency chlorine removal from polyvinyl chloride (PVC) pyrolysis with a gas-liquid fluidized bed reactor. Waste Manage. 2014, 34, 045-050.

[25] Ren, X. H.; Rokni, E.; Sun, R.; Meng, X. X.; Levendis, Y. A. Evolution of Chlorine-bearing Gases during Corn Straw Torrefaction at Different Temperatures. Energ. Fuel. 2017, 31, 713-723.

[26] Liu, G. C.; Liao, Y. F.; Guo, S. D.; Ma, X. Q.; Wu, J. Thermal behavior and kinetics of municipal solid waste during pyrolysis and combustion process. Appl. Therm. Eng. 2016, 98, 400-408.

[27] Rui, S.; Ismail, T. M.; Ren X. H.; El-Salam, M. A. Effect of ash content on the combustion process of simulated MSW in the fixed bed. Waste Manage. 2015, 48, 236-249.

[28] Chen, W. H.; Hsu, H. C.; Lu, K. M.; Lee, W. J.; Lin, T. C. Thermal pretreatment of wood (Lauan) block by torrefaction and its influence on the properties of the biomass. Energ. 2011, $36,012-021$.

[29] Knudsen, J. N.; Jensen, P. A.; Damjohansen, K. Transformation and release to the gas phase of $\mathrm{Cl}$, and $\mathrm{S}$ during combustion of annual biomass. Energ. Fuel. 2004, 18, 385-399.

[30] Montejo, C.; Costa, C.; Ramos, P.; María-del, C. M. Analysis and comparison of municipal solid waste and reject fraction as fuels for incineration plants. Appl. Therm. Eng. 2011, 31, $135-140$.

[31] Zhou, H.; Meng, A. H.; Long, Y. Q.; Li, Q. H.; Zhang, Y. G. An overview of characteristics of municipal solid waste fuel in China: physical, chemical composition and heating value. Energ. Rev. 2014, 36, 107-122.

[32] Johansen, J. M.; Jakobsen, J. G.; Frandsen, F. J.; Glarborg, P. Release of K, C1, and S during pyrolysis and combustion of high-chlorine biomass. Energ. Fuel. 2011, 25, 961-971.

[33] Chen, D. Y.; Zheng, Z. C.; Fu K. X.; Zeng, Z.; Wang, J. J.; Lu, M. T. Torrefaction of biomass stalk and its effect on the yield and quality of pyrolysis products. Fuel 2015, 159, 027-032. 